\title{
Staphylococcus aureus Infections in Injection Drug Users: Risk Factors and Prevention Strategies
}

\author{
S. Bassetti, M. Battegay
}

\begin{abstract}
Infections, in particular soft tissue infections (cellulitis, skin abscesses), are the leading cause for emergency department visits and hospital admissions of drug injection users (IDUs).

Staphylococcus aureus is the most relevant bacterial pathogen in this population. It is the main cause of soft tissue infections and of severe infections such as endocarditis and bacteremia. Moreover, epidemic spread of methicillin-resistant $S$. aureus (MRSA) among IDUs has occurred in Europe and North America. Nasal carriage of $S$. aureus is associated with an increased risk of subsequent $S$. aureus infections, and it has been shown that active IDUs have a higher rate of colonization with $S$. aureus than the general population. However, it is still unknown why an individual carries $S$. aureus. In particular, repeated injections do not appear to be the main predisposing factor for $S$. aureus carriage.

Infections associated with injection drug use are frequently the consequence of the illegal status of street drugs. Harm reduction programs, including needle exchange programs, safer injecting facilities and injection opiate substitution programs can reduce the incidence of infections among severely addicted IDUs.
\end{abstract}

Infection 2004; 32: 163-169

DOI 10.1007/s15010-004-3106-0

\section{Introduction}

Injection drug use is associated with several complications (e.g. infectious diseases, drug overdose, violence) that increase morbidity and mortality rates for injection drug users (IDUs) [1-4]. Previous studies have demonstrated that infections are a leading cause of morbidity and hospitalization among IDUs [3]. In a review of autopsies of 274 hospitalized IDUs in California, United States, infections were the most common cause of death [5]. Infections in IDUs are not only a problem for the individual patient, but may affect the community since bloodborne pathogens (e.g. HIV, hepatitis) and resistant bacteria, such as methicillinresistant Staphylococcus aureus (MRSA), may spread among IDUs and then to non-IDUs. However, complications associated with injection drug use (including many infections) are frequently the consequence of the illegal status of street drugs (contaminated substances, unavailability of sterile injection material, prostitution) rather than of the drug itself [6]. Therefore, opioid substitution programs were developed, with the objective of reducing dependence, morbidity and mortality rates associated with the use of psychoactive substances. In response to the growing problem of the failure of oral substitution treatments to handle addiction in IDUs, injection opiate maintenance programs were started [6-8]. In this review, infections among IDUs, with particular consideration of risk factors and prevention strategies for S. aureus infections, will be discussed.

\section{Infections Leading to Hospitalization of IDUs}

The epidemiology of severe medical complications among IDUs before injection opiate maintenance programs were available was carefully investigated by Scheidegger and Zimmerli [2,3]. They found, in a first retrospective survey of the years 1980 to 1986 , that 269 drug-abusing patients (97\% were IDUs) had 404 admissions to the Department of Medicine of the University Hospital of Basel, Switzerland. $47 \%$ of these patients had at least one infectious complication, and infection was the main cause of hospitalization (31\% of admissions), followed by intoxication with oral drugs $(28 \%)$ and heroin overdose $(17 \%)$. The most frequent infections were lower respiratory tract infections (24\%), viral hepatitis (20\%), HIV infection (14\%), minor

\footnotetext{
S. Bassetti (corresponding author), M. Battegay

Division of Infectious Diseases, University Hospital Basel, CH-4031 Basel, Switzerland; Phone: (+41/61) 265-2525, Fax: -3198,

e-mail: sbassetti@uhbs.ch
} 
genital infection $(11 \%)$, and thrombophlebitis or soft tissue infection (6\%) [3]. The low prevalence of soft tissue infections is explained by the fact that patients admitted to other departments, in particular to the Department of Surgery, were not included in this survey.

In a second retrospective study, charts of 541 IDUs admitted to the same department between 1985 and 1993 were reviewed. An infection was again the main reason for admission among HIV-seropositive IDUs (68\% of admissions; incidence density $81.6 / 1,000$ persons-years), and the second most frequent cause of hospitalization among HIVseronegative IDUs $(33 \% ; 11.3 / 1,000$ persons-years), after intoxication $(34 \%)$ [2].

These data were confirmed by recent studies in other countries. In a prospective cohort study involving 598 IDUs in Vancouver, Canada, between 1996 and 1999, 440 study participants (74\%) visited a hospital emergency department at least once, and $210(35 \%)$ were admitted to the hospital at least one time during the study period. The most common reason for an emergency department visit was a soft tissue infection (cellulitis and skin abscess) (17\% of visits), and the three most common reasons for hospital admissions were pneumonia ( $27 \%$ of admissions), soft tissue infection (18\%), and sepsis ( $8 \%)$. The authors of this study concluded that much of the hospital use was related to complications of injection drug use and may be reduced with the establishment of programs that integrate harm reduction strategies with primary care and addiction treatment [9].

Harm reduction and addiction treatment of severely opioid-dependent drug users are also two of the main goals of the injection opiate substitution programs available in Switzerland, since 1994 [8]. To investigate the impact of such programs on severe infections among participants, a retrospective analysis of hospitalizations due to infection in 175 IDUs for the 3 years before and the period during their participation in an injection opiate maintenance program in Basel, Switzerland was performed (mean duration during program, 2.6 years) [10]. During both periods of the study (i.e. before and during the program) skin infections were the main reason for hospitalization, followed by respiratory tract infections. The injection opiate maintenance treatment did not reduce the incidence or change the spectrum of infections leading to hospitalization among the IDUs studied. However, a majority of these IDUs already routinely used sterile injection material provided by needle exchange programs before entering the injection opiate maintenance program. In addition, other beneficial effects of injection opiate treatment (improvement of health status, reduction of consumption of street drugs, and a decrease in the incidence of HIV) $[6-8,11,12]$ are likely to reduce the risk of infection among IDUs in the long term. On the other hand, the fact that the incidence of infectionrelated hospitalizations during the program did not increase may be interpreted as a stabilization of the health status of the participants.

\section{S. aureus Infections in IDUs}

S. aureus is the most relevant bacterial pathogen in IDUs. In particular, S. aureus is the most common cause of soft tissue infections (skin abscesses, cellulitis) in this population [13]. Soft tissue infections are, as discussed above, one of the main reasons for emergency department visits and hospitalizations of IDUs $[9,10]$, but they are also extremely common among IDUs who did not seek medical care. The skin examination of 1,035 IDUs at admission in the Swiss iv heroin substitution programs revealed, for example, an $18 \%$ prevalence of abscesses and a $29 \%$ prevalence of cellulitis [14]. S. aureus is also the main cause of other severe infections in IDUs. It caused, for example, $61 \%$ of endocarditis and $57 \%$ of bacteremias among IDUs admitted to one hospital in Detroit, Michigan, United States [15, 16], ten of 17 endocarditis episodes $(59 \%)$ in a cohort of 521 IDUs followed for 5 years in Amsterdam, The Netherlands [17], five of seven cases of sepsis (71\%) identified in the study of hospitalized IDUs in Basel, Switzerland, between 1980 and 1986 [3], and it is the most common pathogen causing septic deep vein thrombosis in IDUs [18]. Other infections associated with S. aureus in IDUs are septic arthritis, osteomyelitis, and lung abscesses. Furthermore, an association between injection drug use and MRSA [19], and even outbreaks of MRSA infections among IDUs, have been described in the United States [20] and recently in Switzerland [21,22].

\section{Nosocomial S. aureus Infections and IDUs}

S. aureus is one of the most important causes of nosocomial infections. In a prevalence survey on nosocomial infections conducted in Swiss intensive care units, S. aureus was, overall, the second most frequently isolated microorganism (13\%), after Enterobacteriaceae (28\%), and the main cause for bloodstream (17\%) and surgical site infection (15\%) [23].

Nosocomial bloodstream infections require special consideration, since they are frequent (e.g. $12 \%$ of all nosocomial infections reported in a study on more than 10,000 European intensive care patients) [24], and are associated with significant attributable mortality (4 to $30 \%$ ) and costs (USD 4,000 to USD 40,000 ) [25]. More than $85 \%$ of primary nosocomial bacteremias are intravascular catheterrelated [25] and it has been shown that the mortality rate attributed to catheter-related S. aureus bacteremia (8.2\%) significantly exceeds the rates for other pathogens [26]. These aspects are particularly relevant to hospitalized IDUs, because most of them need a vascular access, frequently a central venous catheter, since peripheral line insertion and even blood drawings are often difficult or impossible in IDUs. Several IDUs use the central venous catheter during hospitalization to inject street drugs, which are often contaminated, thus further increasing the risk of catheter infection, which is already higher in this population because of the higher $S$. aureus colonization rate, of preexistent pathologies of the veins (thrombophlebitis, 
etc.), of the difficult line insertion, and of the frequent use of central venous catheters for drawing of blood samples from these patients [27]. A recent prospective study analyzing 1,379 hospital admissions in Italy confirmed that, at least in HIV-infected patients, active injection drug use is independently associated with nosocomial bloodstream infections [27]. The most common pathogen associated with bacteremia in this study was $S$. aureus $(29.8 \%$ of all nosocomial bloodstream infections and $32.3 \%$ of all catheter-related bloodstream infections).

Thus, strategies focusing on the prevention of catheterrelated bloodstream infections (CRBSI) are particularly important for hospitalized IDUs. Several preventive measures regarding skin disinfection, sterile insertion, dressing, handling and replacement of the catheter have been shown to reduce the incidence of CRBSI and have been recommended $[25,28]$. As a result of the implementation of these measures, during the last 10 years the incidence of intravascular device-associated bloodstream infections has decreased in the United States by nearly 40\% [29]. Educational programs also proved to be very effective in reducing rates of CRBSI [30,31]. An additional option for the prevention of CRBSI is the use of anti-infective catheters [32-34].

\section{Risk Factors for S. aureus Infection in IDUs Nasal S. aureus colonization}

It has previously been shown that active IDUs have a higher rate of colonization with S. aureus (on the skin and nasal) than the general population [35]. This may explain the high incidence of S. aureus infections among IDUs, since the colonized nose provides a reservoir from which the skin is seeded [36], and since nasal carriage is associated with an increased risk of subsequent $S$. aureus infections [37, 38]. The hypothesis that most $S$. aureus infections in IDUs originate from $S$. aureus colonizing the nose is also supported by the findings of two studies investigating the source of $S$. aureus in infected patients. In the first study, Tuazon and Sheagran [39] studied ten IDUs with S. aureus endocarditis. All were S. aureus carriers, and in each case, the phage type of the carried organism matched that of the organism recovered from the blood. In the second study, genotypically identical strains of S. aureus were simultaneously isolated from nasal and wound cultures in $43(81 \%)$ of 53 patients with soft tissue infections who had S. aureus with concordant antimicrobial sensitivity patterns in both nasal and wound sites [40].

It is, however, still unknown why an individual carries S. aureus. A number of host characteristics have been proposed as risk factors for $S$. aureus carriage. Examples include anatomic abnormalities of the nose, certain leukocyte antigens, immunological status, viral infections of the upper respiratory tract, age, ethnicity, hospitalization [37], hormonal status in women [41], previous use of antibiotics [41], use of nasal steroid sprays [42], and the presence of atopic dermatitis [43].
Based on the observation of higher S. aureus carriage rates among patients with insulin-dependent diabetes mellitus, patients on hemodialysis or continuous ambulatory peritoneal dialysis and in iv drug addicts, repeated puncture of the skin by needles has been proposed as a risk factor for nasal $S$. aureus carriage $[37,44,45]$. It was thought this association was further supported by a report showing an increase in the $S$. aureus carriage rate in patients starting allergen-injection immunotherapy, suggesting the repeated injection increased the risk of colonization with S. aureus in this population [45]. In a newer study of 45 outpatients (non-IDUs) undergoing desensitization therapy with allergen injection and 84 healthy controls, the nasal S. aureus carriage rate among patients was also higher than in controls $(46.7 \%$ vs $26.2 \%$; $p=0.019)$. However, the only independent predictor of nasal S. aureus carriage in this study was the presence of atopic dermatitis or eczema (OR 4.4; $95 \%$ CI $1.2-16.0 ; \mathrm{p}=0.02$ ). The probability of nasal $S$. $a u$ reus carriage was $88.9 \%$ for patients receiving allergen injections and having atopic dermatitis or eczema, and $36.1 \%$ for patients receiving allergen injections without atopic dermatitis or eczema [46]. Thus, factors other than the regular use of needles, particularly abnormalities related to the atopic constitution of these patients, may predispose this population for $S$. aureus carriage.

The results of two other studies on IDUs support the hypothesis that regular injections per se are not the main predisposing factor for $S$. aureus carriage. In the first study, 94 IDUs treated in an injection opiate maintenance program (injecting non-contaminated heroin with sterile equipment at least twice daily) had a significantly lower nasal S. aureus carriage rate (22\%) and overall colonization rate (i.e., $S$. aureus carriage in the nose and/or pharynx and/or the skin) (39\%) than 70 IDUs participating in a conventional oral methadone program (respectively $43 \%$ and $60 \% ; p=0.005$ and $p=0.009$ ). In a multivariate model, being in the oral methadone program was the only significant risk factor for S. aureus carriage (OR 2.27; 95\% CI 1.19$4.31 ; \mathrm{p}=0.012)$. It is important to note that $66 \%$ of the patients in the oral methadone program continued to use iv street drugs [47]. In the second study of 217 active and former drug users, no association between iv drug use and nasal colonization by $S$. aureus was found, while nasal $S$. aureus carriage was independently correlated with inhalational drug use in HIV-infected persons [48]. These findings suggest that injection of contaminated drugs and inhalational drug use may promote nasal $S$. aureus colonization, probably by damaging the nasal mucosa, since damaged nasal mucosa is more likely to become colonized by $S$. $a u$ reus [49].

\section{Contaminated Drugs and Drug-Use Paraphernalia} Organisms causing infections in IDUs may come from contaminated needles or saliva, when the needle is licked before injection, or the injection site is "cleaned" with saliva. This mechanism of infection has been associated for ex- 
ample with cases of endocarditis or osteomyelitis caused by Eikenella corrodens [50,51]. Lemon juice used in heroin abuse has been implicated as a source of Candida albicans in outbreaks of systemic candidiasis in IDUs [52]. Epidemics of Pseudomonas aeruginosa endocarditis have been described in IDUs, mainly abusers of pentazocine and tripelenamine, and are presumably associated with the mixing of drugs in contaminated water [53]. Finally, a recent outbreak of a clonal strain of group A streptococcus among drug users in Bern, Switzerland, may have been caused by contaminated cocaine or its containers [54], and an epidemic of wound botulism in California, may have resulted from contamination of black tar heroin most likely when it was diluted ("cut"), possibly with soil [55]. Inhalation druguse paraphernalia were identified as potential vehicles of transmission of S. aureus in inhalation drug users [56]. However, contaminated drugs or paraphernalia have probably only a minor role in the transmission of S. aureus. Tuazon et al. [57] did not find S. aureus contamination of either street heroin or injection paraphernalia, and showed that most samples of street heroin had antibacterial effects against $S$. aureus and Bacillus cereus, possibly because of the quinine content of the drug mixture [58]. Also in a recent study, only one of 58 heroin samples examined in the United Kingdom yielded S. aureus [59].

\section{Drug Use Environment}

It has previously been shown that close personal contact may facilitate outbreaks of S. aureus skin infections, in particular if involved individuals frequently present minor skin wounds. Such epidemics were described, for example, among members of football and wrestling teams [60,61], or among river rafting guides who shared communal housing [62]. Similarly, S. aureus may spread among drug users in shooting galleries, crack houses or other sites where drugs are consumed, and where hygiene is usually poor. Indeed, Craven et al. [63] reported an MRSA outbreak among IDUs who frequented the same shooting gallery, and frequent and close social contacts was considered to be the most likely explanation for the epidemic spread of a single clone of MRSA among IDUs in Zurich, Switzerland [21].

\section{General Risk Factors for Infections in IDUs}

In addition to risk factors that specifically increase the risk of S. aureus infections, other characteristics or habits of IDUs are associated with bacterial infections in general. Subcutaneous or intramuscular injection of drugs ("skinpopping"), injection of a cocaine and heroin mixture ("speedball"), use of a dirty needle, higher frequency of injection, and drawing blood into the syringe before injection of drugs ("booting") (in particular in individuals who do not engage in skin-popping) have been identified as risk factors for soft-tissue abscesses [17, 64]. Women are at greater risk for skin abscesses, presumably because female IDUs have fewer visible veins than men do and may have greater difficulty in accessing their veins [17]. Infection with
HIV was associated with soft-tissue abscesses in some, but not in all studies [17, 64]. Finally, endocarditis in IDUs was associated with HIV infection, previous history of endocarditis [17], and cocaine use [65]. It is unknown whether the increased risk related to cocaine is caused by systemic or immunosuppressive effects of cocaine or by injection habits (more frequent injections).

\section{Prevention of S. aureus Infections in IDUs}

The most effective means of preventing infections among IDUs is, obviously, treatment of drug abuse, with consequent reduction or termination of injection drug use. Improving the quality of treatment services by adding counseling, medical care, and psychosocial services to a methadone therapy, for example, can significantly reduce drug use [66]. Further preventive strategies are directed toward risk factors identified for infections in IDUs. Simple skin cleaning before injection decreases the risk of soft-tissue abscesses and endocarditis [64, 67]. Needle exchange programs reduce the use of dirty needles and the incidence of abscesses [68], and may be even more effective if combined with primary health care delivery systems [69], with a soft tissue infection clinic [70], or with safer injecting facilities where IDUs can also inject pre-obtained illicit drugs [71]. Finally, injection opiate substitution programs for severely addicted IDUs improve health status and social functioning, reduce the self-reported use of illicit drugs and criminal activity $[6-8,11]$, may decrease the incidence of HIV and hepatitis A [12], and reduce the prevalence of skin abscesses and cellulitis [14].

In conclusion, IDUs are at high risk for both community-acquired and nosocomial infections. The main bacterial pathogen causing these infections is $S$. aureus. The high incidence of $S$. aureus infections among IDUs can be explained, at least in part, by the high $S$. aureus colonization rate in this population, which predisposes for subsequent infections with this organism. S. aureus is not only a threat because of the relevant morbidity and costs associated with S. aureus infections, but also because of the spread of antibiotic-resistant strains, particularly of MRSA. Continuous surveillance of the epidemiologic situation is necessary to rapidly identify the beginning of MRSA outbreaks among IDUs.

The understanding of the mechanisms leading to S. aureus colonization would allow implementation of efficacious prevention strategies for IDUs, but also for other patients at risk for S. aureus colonization and infection (e.g. insulin-dependent diabetics, hemodialysis patients). However, these mechanisms are still unknown. In particular, repeated injections do not appear to be the main cause of increased S. aureus carriage, and further studies are needed to investigate this question.

Infections associated with iv drug use are frequently the consequence of the illegal status of street drugs. Harm reduction programs including needle exchange programs, safer injecting facilities and injection opiate substitution 
programs can reduce the incidence of infections among severely addicted IDUs.

\section{Acknowledgements}

S. Bassetti was supported by grants from the University of Basel (Sonderprogramm zur Förderung des akademischen Nachwuchses) and from the Department of Internal Medicine (VFWAWF), University Hospital Basel, Switzerland.

\section{References}

1. Cherubin CE, Sapira JD: The medical complications of drug addiction and the medical assessment of the intravenous drug users: 25 years later. Ann Intern Med 1993; 119: 1017-1028.

2. Scheidegger $C$, Zimmerli W: Incidence and spectrum of severe medical complications among hospitalized HIV-seronegative and HIV-seropositive narcotic drug users. AIDS 1996; 10: 1407-1414.

3. Scheidegger C, Zimmerli W: Infectious complications in drug addicts: 7-year review of 269 hospitalized narcotic abusers in Switzerland. Rev Infect Dis 1989; 11: 486-493.

4. Marzuk PM, Tardiff K, Leon AC, Hirsch CS, Stajic M, Portera L, Hartwell N, Iqbal MI: Fatal injuries after cocaine use as a leading cause of death among young adults in New York City. N Engl J Med 1995; 332: 1753-1757.

5. Klatt EC, Mills NZ, Noguchi TT: Causes of death in hospitalized intravenous drug abusers. J Forensic Sci 1990; 35: 1143-1148.

6. Perneger TV, Giner F, del Rio M, Mino A: Randomised trial of heroin maintenance programme for addicts who fail in conventional drug treatments. BMJ 1998; 317: 13-18.

7. World Health Organization: Report of the external panel on the evaluation of the Swiss scientific studies of medically prescribed narcotics to drug addicts. Geneva: World Health Organization, April 1999.

8. Rehm J, Gschwend P, Steffen T, Gutzwiller F, Dobler-Mikola A, Uchtenhagen A: Feasibility, safety, and efficacy of injectable heroin prescription for refractory opioid addicts: a follow-up study. Lancet 2001; 358: 1417-1420.

9. Palepu A, Tyndall MW, Leon H, Muller J, O'Shaughnessy MV, Schechter MT, Anis AH: Hospital utilization and costs in a cohort of injection drug users. CMAJ 2001; 165: 415-420.

10. Bassetti S, Hoffmann M, Bucher HC, Fluckiger U, Battegay M: Infections requiring hospitalization of injection drug users who participated in an injection opiate maintenance program. Clin Infect Dis 2002; 34: 711-713.

11. Steffen T, Uchtenhagen A, Gutzwiller F, Dobler-Mikola A, Blättler $R$, PROVE Team: Die heroingestützte Behandlung von Opiatabhängigen: Erfahrungen aus den Schweizerischen Versuchen für eine ärztliche Verschreibung von Betäubungsmitteln (PROVE). Internist (Berl) 1999; 40: 651-656.

12. Naef MR, Bucher HC, Erb P, Gyr N, Bassetti S, Battegay M: Reduced infections with HIV and hepatitis A during a Swiss intravenous opiate maintenance program. J Acquir Immune Defic Syndr 1999; 21: 349-351.

13. Summanen PH, Talan DA, Strong C, McTeague M, Bennion R, Thompson JE Jr, Vaisanen ML, Moran G, Winer M, Finegold SM: Bacteriology of skin and soft-tissue infections: comparison of infections in intravenous drug users and individuals with no history of intravenous drug use. Clin Infect Dis 1995; 20 Suppl. 2: S 279-282.

14. Conrad C, Steffen T, Gutzwiller F: Die Entwicklung von Hauterkrankungen bei intravenösen Drogenabhängigen in der heroingestützten Behandlung. Schweiz Rundsch Med Prax 2000; 89: 1899-1906.

15. Levine DP, Crane LR, Zervos MJ: Bacteremia in narcotic addicts at the Detroit Medical Center. II. Infectious endocarditis: a prospective comparative study. Rev Infect Dis 1986; 8: 374-396.

16. Crane LR, Levine DP, Zervos MJ, Cummings G: Bacteremia in narcotic addicts at the Detroit Medical Center. I. Microbiology, epidemiology, risk factors, and empiric therapy. Rev Infect Dis 1986; 8:364-373

17. Spijkerman IJB, van Ameijden EJC, Mientjes GHC, Coutinho RA, van den Hoek A: Human immunodeficiency virus infection and other risk factors for skin abscesses and endocarditis among injection drug users. J Clin Epidemiol 1996; 49: 1149-1154.

18. Fäh F, Zimmerli W, Jordi M, Schoenenberger RA: Septic deep venous thrombosis in intravenous drug users. Swiss Med Wkly 2002; 132: 386-392.

19. Markowitz N, Quinn EL, Saravolatz LD: Trimethoprim-sulfamethoxazole compared with vancomycin for the treatment of Staphylococcus aureus infection. Ann Intern Med 1992; 117: 390-398.

20. Saravolatz LD, Markowitz N, Arking L, Pohlod D, Fisher E: Methicillin-resistant Staphylococcus aureus. Epidemiologic observations during a community-acquired outbreak. Ann Intern Med 1982; 96: 11-16.

21. Fleisch F, Zbinden R, Vanoli C, Ruef C: Epidemic spread of a single clone of methicillin-resistant Staphylococcus aureus among injection drug users in Zurich, Switzerland. Clin Infect Dis 2001; 32: 581-586.

22. Oechslin E, Reinhart WH, Gujer AR, Ritzler E, Fleisch F: Ausweitung der MRSA-Epidemie unter Drogenbenutzern in der Schweiz. [abstr.]. Schweiz Med Forum 2003; Suppl. 12: 61S.

23. Harbarth S, Ruef C, Francioli P, Widmer A, Pittet D, for the Swiss-Noso network. Nosocomial infections in Swiss university hospitals: a multi-centre survey and review of the published experience. Schweiz Med Wochenschr 1999; 129: 1521-1528.

24. Vincent JL, Bihari DJ, Suter PM, Bruining HA, White J, NicolasChanoin MH, Wolff M, Spencer RC, Hemmer M: The prevalence of nosocomial infection in intensive care units in Europe. Results of the European Prevalence of Infection in Intensive Care (EPIC) Study. JAMA 1995; 274: 639-644.

25. Eggimann P, Pittet D: Overview of catheter-related infections with special emphasis on prevention based on educational programs. Clin Microbiol Infect 2002;8: 295-309.

26. Mermel LA, Farr BM, Sherertz RJ, Raad II, O'Grady N, Harris JS, Craven DE: Guidelines for the management of intravascular catheter-related infections. Clin Infect Dis 2001; 32: 1249-1272.

27. Petrosillo N, Viale P, Nicastri E, Arici C, Bombana E, Casella A, Cristini F, De Gennaro M, Dodi F, Gabutti A, Guttuso G, Irato L, Maggi P, Pallavicini F, Pan A, Pantaleoni M, Ippolito G, for Gruppo HIV e Infezioni Ospedaliere: Nosocomial bloodstream infections among human immunodeficiency virus-infected patients: incidence and risk factors. Clin Infect Dis 2002; 34: 677-685.

28. Centers for Disease Control and Prevention: Guidelines for the prevention of intravascular catheter-related infections. MMWR 2002; 51 10: 1-32.

29. Crnich CJ, Maki DG: The promise of novel technology for the prevention of intravascular device-related bloodstream infection. I. Pathogenesis and short-term devices. Clin Infect Dis 2002; 34: 1232-1242.

30. Sherertz RJ, Ely EW, Westbrook DM, Gledhill KS, Streed SA, Kiger B, Flynn L, Hayes S, Strong S, Cruz J, Bowton DL, Hulgan T, Haponik EF: Education of physicians-in-training can decrease 
the risk for vascular catheter infection. Ann Intern Med 2000; 132: 641-648.

31. Eggimann P, Harbarth S, Constantin MN, Touveneau S, Chevrolet JC, Pittet : Impact of a prevention strategy targeted at vascularaccess care on incidence of infections acquired in intensive care. Lancet 2000; 355: 1864-1868.

32. Maki DG, Stolz SM, Wheeler S, Mermel LA: Prevention of central venous catheter-related bloodstream infection by use of an antiseptic-impregnated catheter. A randomized, controlled trial. Ann Intern Med 1997; 127: 257-266.

33. Darouiche RO, Raad II, Heard SO, Thornby JI, Wenker OC, Gabrielli A, Berg J, Khardori N, Hanna H, Hachem R, Harris RL, Mayhall G: A comparison of two antimicrobial-impregnated central venous catheters. N Engl J Med 1999; 340: 1-8.

34. Bassetti S, Hu J, D’Agostino RB Jr, Sherertz RJ: Prolonged antimicrobial activity of a catheter containing chlorhexidine-silver sulfadiazine extends protection against catheter infections in vivo. Antimicrob Agents Chemother 2001; 45: 1535-1538.

35. Tuazon CU, Sheagren JN: Increased rate of carriage of Staphylococcus aureus among narcotic addicts. J Infect Dis 1974; 129: 725-727.

36. White A: Relation between quantitative nasal cultures and dissemination of staphylococci. J Lab Clin Med 1961; 58: 273-277.

37. Kluytmans J, van Belkum A, Verbrugh $\mathrm{H}$ : Nasal carriage of Staphylococcus aureus: epidemiology, underlying mechanisms, and associated risks. Clin Microbiol Rev 1997; 10: 505-520.

38. von Eiff C, Becker K, Machka K, Stammer H, Peters G: Nasal carriage as a source of Staphylococcus aureus bacteremia. $\mathrm{N}$ Engl J Med 2001; 344: 11-16.

39. Tuazon CU, Sheagren JN: Staphylococcal endocarditis in parenteral drug abusers: source of the organism. Ann Intern Med 1975; 82: 788-79o.

40. Charlebois ED; Young D, Harris H, Haller B, Moss N, Bangsberg DR, Perdreau-Remington F: Genetically identical Staphylococcus aureus simultaneously isolated from nasal culture and soft-tissue infection. 42nd Interscience Conference on Antimicrobial Agents and Chemotherapy, San Diego, September 27-30, 2002, abstr. K-94.

41. Winkler J, Block C, Leibovici L, Faktor J, Pitlik SD: Nasal carriage of Staphylococcus aureus: correlation with hormonal status in women. J Infect Dis 1990; 162: 1400-1402.

42. Gittelman PD, Jacobs JB, Lebowitz AS, Tierno PM Jr: Staphylococcus aureus nasal carriage in patients with rhinosinusitis. Laryngoscope 1991; 101: 733-737.

43. Aly R, Maibach $\mathrm{HI}$, Shinefield HR: Microbial flora of atopic dermatitis. Arch Dermatol 1977; 113: 780-782.

44. Perl TM, Golub JE: New approaches to reduce Staphylococcus aureus nosocomial infection rates: treating $S$. aureus nasal carriage. Ann Pharmacother 1998; 32 (Suppl.): S7-S16.

45. Kirmani N, Tuazon CU, Alling D: Carriage rate of Staphylococcus aureus among patients receiving allergy injections. Ann Allergy 1980; 45: 235-237.

46. Bassetti S, Dunagan DP, D’Agostino RB Jr, Sherertz RJ: Nasal carriage of Staphylococcus aureus among patients receiving allergen-injection immunotherapy: associated factors and quantitative nasal cultures. Infect Control Hosp Epidemiol 2001; 22: 741-745.

47. Bassetti S, Wolfisberg L, Jaussi B, Frei R, Kuntze MF, Battegay M, Widmer AF: S. aureus carriage among injection drug users: lower prevalence in an injection heroin maintenance program than in an oral methadone program. Infect Control Hosp Epidemiol; in press.

48. Holbrook KA, Klein RS, Hartel D, Elliot DA, Barsky TB, Rothschild
LH, Lowy FD: Staphylococcus aureus nasal colonization in HIVseropositive and HIV-seronegative drug users. J Acquir Immune Defic Syndr Hum Retrovirol 1997; 16: 301-306.

49. Lowy FD, Miller M: New methods to investigate infectious disease transmission and pathogenesis - Staphylococcus aureus disease in drug users. Lancet Infect Dis 2002; 2: 605-612.

50. Olopoenia LA, Mody V, Reynolds M: Eikenella corrodens endocarditis in an intravenous drug user: case report and literature review. J Natl Med Assoc 1994; 86: 313-315.

51. Swisher LA, Roberts JR, Glynn MJ: Needle licker's osteomyelitis. Am J Emerg Med 1994; 12: 343-346.

52. Newton-John HF, Wise K, Looke DF: Role of lemon in disseminated candidiasis of heroin abusers. Med J Aust 1984; 140: 780-781.

53. Wieland M, Lederman MM, Kline-King C, Keys TF, Lerner PI, Bass SN, Chmielewski R, Banks VD, Ellner JJ: Left-sided endocarditis due to Pseudomonas aeruginosa. A report of 10 cases and review of the literature. Medicine (Baltimore) 1986; 65: 180-189.

54. Böhlen LM, Mühlemann K, Dubuis O, Aebi C, Täuber MG: Outbreak among drug users caused by a clonal strain of group $A$ Streptococcus. Emerg Infect Dis 2000; 6: 175-179.

55. Passaro DJ, Benson Werner S, McGee J, Mac Kenzie WR, Vugia DJ: Wound botulism associated with black tar heroin among injecting drug users. JAMA 1998; 279: 859-863.

56. Quagliarello B, Cespedes C, Miller M, Toro A, Vavagiakis P, Klein RS, Lowy FD: Strains of Staphylococcus aureus obtained from drug-use networks are closely linked. Clin Infect Dis 2002; 35: 671-677.

57. Tuazon CU, Hill R, Sheagren JN: Microbiologic study of street heroin and injection paraphernalia. J Infect Dis 1974; 129: 327-329.

58. Tuazon CU, Miller H, Shamsuddin D: Antimicrobial activity of street heroin. J Infect Dis 1980; 142: 944.

59. McLauchlin J, Mithani V, Bolton FJ, Nichols GL, Bellis MA, Syed O, Thomson RPM, Ashton JR: An investigation into the microflora of heroin. J Med Microbiol 2002; 51: 1001-1008.

6o. Pollard JG: The Staphylococcus plagues a football team. J Am Coll Health 1967; 15: 234-238.

61. Lindenmayer JM, Schoenfeld S, O'Grady R, Carney JK: Methicillinresistant Staphylococcus aureus in a high school wrestling team and the surrounding community. Arch Intern Med 1998; 158: 895-899.

62. Decker MD, Lybarger JA, Vaughn WK, Hutcheson RH, Schaffner W: An outbreak of staphylococcal skin infections among river rafting guides. Am J Epidemiol 1986; 124: 969-976.

63. Craven DE, Rixinger AI, Goularte TA, McCabe WR: Methicillin-resistant Staphylococcus aureus bacteremia linked to intravenous drug abusers using a "shooting gallery". Am J Med 1986; 80: 770-776.

64. Murphy EL, DeVita D, Liu H, Vittinghoff E, Leung P, Ciccarone DH, Edlin BR: Risk factors for skin and soft-tissue abscesses among injection drug users: a case-control study. Clin Infect Dis 2001; 33:35-40.

65. Chambers HF, Morris DL, Tauber MG, Modin G: Cocaine use and the risk for endocarditis in intravenous drug users. Ann Intern Med 1987; 106: 833-836.

66. McLellan AT, Arndt IO, Metzger DS, Woody GE, O'Brien CP: The effects of psychosocial services in substance abuse treatment. JAMA 1993; 269: 1953-1959.

67. Vlahov D, Sullivan M, Astemborski J, Nelson KE: Bacterial infections and skin cleaning prior to injection among intravenous drug users. Public Health Rep 1992; 107: 595-598.

68. Hart GJ, Carvell AL, Woodward N, Johnson AM, Williams P, Parry J: 
Evaluation of needle exchange in central London: behaviour change and anti-HIV status over one year. AIDS 1989; 3: 261-265.

69. Pollack HA, Khoshnood K, Blankenship KM, Altice FL: The impact of needle exchange-based health services on emergency department use. J Gen Intern Med 2002; 17: 341-348.
70. Grau LE, Arevalo S, Catchpool C, Heimer R: Expanding harm reduction services through a wound and abscess clinic. Am J Public Health 2002; 92: 1915-1917.

71. Ronco C, Spuhler G, Coda P, Schopfer R: Evaluation of street facilities I, II and III in Basel. Soz Praventivmed 1996; 41 Suppl. 1: S58-68. 